\title{
Do policy instruments matter? Governments' choice of policy mix and higher education performance in Western Europe
}

\author{
Giliberto Capano $^{1 *}$, Andrea Pritoni ${ }^{2}$ and Giulia Vicentini ${ }^{3}$ \\ ${ }^{1}$ Department of Political and Social Sciences, University of Bologna, Italy, ${ }^{2}$ Department of Cultures, \\ Politics, and Society, University of Torino, Italy and ${ }^{3}$ Department of Political and Social Sciences, \\ University of Bologna, Italy \\ ${ }^{*}$ Corresponding author. Email: giliberto.capano@unibo.it
}

(Received 15 December 2017; revised 18 January 2019; accepted 29 January 2019; first published online 5 March 2019)

\begin{abstract}
Governments pursue their goals by adopting various mixes of policy instruments. This article proposes a specific operationalisation of these mixes and applies it to the analysis of reforms that many Western European governments have pursued, as they have adopted a similar policy design in their higher education systems (HESs) over the last 20 years. In fact, although these policies have similar templates, performance indicators exhibit remarkable variation between countries. Thus, by applying Qualitative Comparative Analysis to a large data set containing all changes in policy instruments undertaken in the last 20 years in 12 HESs in Western Europe, this article explores the possibility that differences in performance across national HESs could be associated ceteris paribus - with different policy mixes. This article finds not only that the common template has been applied through very different national policy mixes but also that only a few instruments are regularly linked to good teaching performance, regardless of the other components of the actual policy mix.
\end{abstract}

Keywords governance reforms; higher education; performance; policy instruments; QCA; Western Europe

\section{Introduction}

Public policy studies offer different typologies of governance modes, each of which attempts to theoretically order the ways in which public policies are coordinated and steered (for all typologies, see, Considine and Lewis 1999; Treib et al. 2007; Capano 2011; Howlett 2011; Tollefson et al. 2012). All these classifications share not only their adoption of the three fundamental, albeit differently arranged, principles of social coordination (hierarchy, market and network) but also the tendency to associate specific sets of policy instruments with each of the designed governance modes in a long-lasting or relatively long-lasting policy style. This tendency refers to the basic theoretical problem in which people select policy instruments that are congruent with a governance mode and do so in a more or 
less predictable way, leading to a characteristic style or manner of formulating and implementing policies.

Any selection of policy instruments is characterised by an intrinsic policy-mix trend (Bressers et al. 2005; Howlett 2005) and, as such, should be considered the result of a miscellany of different ideas, interests and technologies, and deemed institutionalised in certain specific, recurrent contingencies.

Some mixes are thought to perform better than others, but it remains unclear why this is the case. For example, all studies of "good governance" promoted by the Organization for Economic Cooperation and Development (OECD 2007, 2010) and other international organisations tend to focus on the best mix of policy instruments adopted in pursuit of certain specific policy goals, but they provide few indications on why the chosen tools constitute such an optimal arrangement.

Thus, there is an increasing problem in the governance literature regarding the real policy effectiveness of the process of continuous shifting that has characterised, in a comparative perspective and over the last three decades, governance modes in public policy and public administration. We know that governance modes have changed, and we know that these changes have taken shape via different policy mixes. However, we know very little about the characteristics and the actual consequences of these same mixes.

In this article, we propose to unravel this double-sided problem by empirically focussing on governance reforms in Western European higher education systems (HESs). According to the mainstream literature related to governance changes in higher education (HE) (Huisman 2009; Paradeise et al. 2009; Capano and Regini 2014; Dobbins and Knill 2014; Shattock 2014), Western European governments have redesigned governance systems to make HE institutions more accountable by intervening with the introduction of rules that govern the allocation of public funding and tuition fees, the recruitment of academics, and the evaluation and accreditation of institutions. To accomplish this goal, these countries have turned to a similar policy formula (the so-called "steering at a distance" governance arrangement).

However, according to contrasting results in the literature, there is no clear evidence regarding either the composition of the adopted policy formulas or whether and how the new governance template can be associated with satisfactory results. We address this gap by assuming a policy instrument perspective, meaning that the actual national interpretation that each country has given to the common policy template in reforming HE governance can be assessed by focussing on the specific combinations of policy instruments that have been adopted at the national level. To understand these combinations and, thus, the specific content of the adopted policy design, we propose a specific operationalisation of policy instruments whose constitutive logic could also be applied to other policy fields.

Furthermore, we explore the hypothesis that the way specific policy tools are set together matters for policy performance. We are fully aware that the link between policies' content (policy instruments) and their outcomes is indirect and limited (Koontz and Thomas 2012) and that policy performance is driven by many factors (in the case of HE policy, factors such as the percentage of public spending and the socio-economic, cultural background of families, external and internal shocks, and financial retrenchments matter). However, the main way governments can steer their policy systems is to adopt specific sets of policy tools to address the behaviour of specific targets and beneficiaries; thus, the policy mixes that governments 
recurrently design could help to readdress the way that policies work and their performance. Therefore, policy mixes can be intended as possible explanatory conditions (among others), and the composition of the actual set of adopted policy instruments could make the difference or, at least, signal something of relevance from an explanatory point of view.

Being conscious of the intrinsic limitations of the research design, our main goal is to demonstrate the degree to which the research design we have followed can be promising in filling the existing knowledge gap concerning the assessment of (1) how policy instruments are really mixed together and (2) their association with the effects of governance reforms on public policy.

We have pursued this research strategy by collecting and analysing data on the regulatory changes in $\mathrm{HE}$ in 12 countries over the last 20 years (1995-2014).

The article is structured as follows. In the second section, we present our policy instrument framework, while in the third section, we introduce the research design. The fourth section presents the results of the empirical analysis, which are then discussed in the fifth section. Finally, the conclusion summarises our preliminary results and proposes directions for future research.

\section{Governance arrangements and systemic performance in HE: an instrumental perspective}

\section{Governance reforms in $H E$}

Many scholars have underlined the apparent convergence towards the "steering at a distance" mode in HE in recent decades (Braun and Merrien 1999; Huisman 2009; Paradeise et al. 2009; Shattock 2014). This governance arrangement is characterised by mixing the following instruments together: financial incentives to pursue specific outputs and outcomes in teaching and research, student loans, accreditation, ex post evaluation conducted by public agencies, contract benchmarking and provisions by the law for greater institutional autonomy (Gornitzka et al. 2005; Lazzaretti and Tavoletti 2006; Maassen and Olsen 2007; Trakman 2008; Capano 2011; Capano and Turri 2017). However, this convergence certainly works to support general principles (more institutional autonomy, more evaluation and more competition), while the concrete ways through which the policies are generated seem to be quite diverse (Capano and Pritoni 2019). Nonetheless, this diversity, at least in terms of the concrete composition of the adopted policy instruments, has never been clarified.

Furthermore, it should be noted that in terms of policy performance, the effects of these governance shifts have not been clearly assessed. In fact, the literature on HESs' performance has focussed mainly on a few aspects as key determinants of policy success (or failure): the mechanism of funding (Liefner 2003), the total amount of public funding (Winter-Ebmer and Wirz 2002; Horeau et al. 2013; Williams et al. 2013), full institutional autonomy (Aghion and Dewatripont 2008), partisan dynamics (Ansell 2008), stratification (Willemse and De Beer 2012) and the type of loan system adopted (Flannery and O'Donoghue 2011). However, this research strategy simply assesses whether certain variables have the power to influence the probability of the outcome changing as expected on average at the population level, regardless of interactions. These types of explanatory results seem weak and generally risk remaining fairly superficial. The salient point here is that 
focusing on a single dimension to assess the performance capacity of a governance arrangement is quite misleading. For example, the effects of shifting from a centralised governance system to one in which universities are more autonomous cannot be analysed without contextualising the change within its specific configuration, that is, by considering the other relevant instrumental dimensions (e.g. how universities are funded, the system of degree accreditation, whether a national research evaluation assessment is present, etc.).

Overall, despite the significant governance shifts in $\mathrm{HE}$, there is currently a lack of knowledge on both the actual nature of these changes in terms of existing combinations of adopted instruments and the policy performance of the new governance arrangements.

\section{Governance arrangements as a set of policy instruments}

Policies are steered by specific governance arrangements composed of rules, instruments, actors, interactions and values (Howlett 2009, 2011; Tollefson et al. 2012; Capano et al. 2015). The implicit assumption of the governance literature is that different governance modes or arrangements deliver different results in terms of policy outcomes. However, empirical evidence on this issue has been lacking, especially because the main analytical focus in public policy has been the process of changing governance arrangements in terms of their content with respect to the actors involved, the distribution of power, and the adoption of "new" policy instruments. Thus, there has not been enough focus on the results of these governance shifts in mainstream public policy.

However, there is an increasing awareness that pure types of governance arrangements do not actually work; instead, the main principles of coordination (hierarchy, market and network) are combined in various ways. All governance arrangements are essentially hybrids and are characterised as working through policy mixes, that is, policy instruments belonging to "different" instrument categories or pertaining to different policy paradigms/beliefs/systems/ideologies (Howlett 2005; Ring and Schroter-Schlaack 2010; Capano et al. 2012). Thus, an existing set of adopted policy instruments can be conceptualised as specific portfolios, settings and combinations of different types of policy instruments associated with different working logics (Jordan et al. 2012; Schaffrin et al. 2014; Howlett and Del Rio 2015).

However, how can the content of these policy mixes be described and understood, and how can their policy performance be assessed? In an attempt to fill these theoretical and empirical gaps, we adopt a bottom-up perspective by focussing on the basic unit of any governance mode - the policy instruments that can be adopted - and their possible combinations. This approach seems quite realistic; policy instruments are the operational, performance-related dimensions of governance arrangements.

Accordingly, we operationalise systemic governance arrangements in terms of adopted policy instruments and therefore as specific sets of techniques or means by which governments try to affect the behaviour of policy actors to direct them towards the desired results (Linder and Peters 1990; Vedung 1998; Howlett 2000; Salamon 2002).

There are numerous classifications by which policy tools can be ordered based on different criteria of analytical distinction, from coercion to the type of 
governmental source adopted (Hood 1983; Phidd and Doern 1983; Ingram and Schneider 1990; Vedung 1998; Howlett 2011). All these typologies suggest different families of instruments. Our research framework focuses on the capacity of policy instruments to induce specific behaviours; thus, we need to consider the nature of the instruments and examine the different ways through which they induce action towards the expected result. In conducting this examination, we are inspired by the classical theorisation of Vedung (1998). When focussing on the nature of substantive policy instruments, Vedung grouped these instruments by the basic inducement on which they relied to foster compliance.

By adopting this perspective, we can delimit four distinct families of substantial policy instruments that have different, nonoverlapping capacities to induce behaviours: regulation, expenditure, taxation and information. ${ }^{1}$ Each family is associated with a specific inducement. Regulation induces behaviour control; expenditure induces remuneration; taxation - depending on the way it is designed - can engender behaviour control and remuneration; and information offers persuasion. Notably, all four families of tools can be employed by applying different methods of coercion that are dependent on how free individuals are to choose alternatives. Regulation can be quite strong or weak according to the type of behavioural prescriptions provided. Expenditure can lack coercion in the case of subsidies but be very demanding when delivering targeted funding. Taxation can be quite coercive when a general tax increase is established, but it can also have a low degree of coercion when many targeted tax exemptions exist. Information can be coercive when compulsory disclosure is imposed or lack strong coercion when monitoring is applied.

The four families of substantial policy instruments we have decided to consider, as well as the types proposed by other policy instrument classifications, represent very general instrumental principles (which need to take specific forms to be practically applied): they are "families of individual instruments sharing similar characteristics" (Bouwma et al. 2016, 216).

Thus, according to Salamon (2002), the "shape" through which the substantial instrument is designed to deliver the expected result is the important factor in terms of policy impact and potential performance. For every type of family of substantial policy instruments, there are different shapes of delivery that offer actual outlets through which those substantial instruments can affect reality. In addition, these instrumental shapes should be considered the basic analytical unit when assessing how policies are made and, thus, which types of governance arrangements actually work in terms of policy performance.

Accordingly, the important factors in detecting the adoption of a regulation instrument are the various forms through which regulations can be designed: for example, by imposing a specific behaviour, enlarging the range of opportunities or establishing specific public organisations. Expenditures can be delivered through

\footnotetext{
${ }^{1}$ In our perspective, taxation can be considered an autonomous substantial instrument. We are aware that in other typologies, taxation is the chief component of broader instruments. Phidd and Doern (1983) considered taxation to be a means of regulation (as it implies high coercion), while Hood (1983), following the same reasoning, held partially to the "authority" type (i.e. user charges) and partially to the treasury type (i.e. tax exemptions, tax expenditures). We believe that expenditure and taxation have different political and economic characteristics and present different ways of inducing or restraining institutional and individual behaviour (Woodside 1983).
} 
grants, subsidies, loans, lump sum transfers and targeted transfers, among other shapes. Taxation can imply fees, user charges and exemptions, among others. Information can take the shape of neutral administrative disclosures, monitoring, diffusion, etc.

Each of these instruments' shapes carries specific potential effects that cannot be measured alone because they should be considered in relation to the other tools that compose the actual set of adopted policy instruments. Understanding the distinct shapes that various types of substantive policy instruments can take when delivered is essential to grasping how governments change the instrumental side of governance arrangements over time. ${ }^{2}$ There are three dimensions in which this distinction is helpful.

The first dimension is descriptive. By focussing on the different shapes of policy instruments, the usual description can acquire a more detailed reconstruction of shifts in governance compared to the usual distinction of more or less market, more or less hierarchy, more or less regulation, more or fewer expenditures, etc.

The second dimension is analytical. Due to the focus on the basic shapes through which substantial instruments are delivered, the policy mix concept can be operationalised in a very effective and realistic way. Thus, the eventual relevant differences can be assessed in terms of policy settings because the content of policy mixes can be grasped in a very detailed manner.

The third dimension is clearly exploratory, with a particular emphasis on the possible explanatory relevance of policy instruments for performance. If policy performance is assumed to be conditioned by - among other factors - the adopted set of policy instruments, a detailed operationalisation of the substantial instruments should uncover which combinations of instruments actually work, which can lead to a better reconceptualisation of the (many) determinants of policy performance and of their interactions.

This perspective seriously considers the suggestions of those scholars who have observed how the actual set of adopted policy instruments is the consequence of a diachronic accumulation. Thus, we need to analyse the full package instead of a single type of policy instrument (Hacker 2004; Pierson 2004; Huitema and Meijerink 2009; Tosun 2013; Schaffrin et al. 2014).

Therefore, from a theoretical perspective, the decision to focus on the instrumental side of governance arrangements to measure their potential impact on policy performance encourages proceeding by using combinatory logic: when the expected effect, namely, policy performance, is assumed to depend on - among other things - a combination of multiple conditions (i.e. specific settings of policy instruments), then a complex causality principle is at work. For this reason, we decided to turn to a Qualitative Comparative Analysis (QCA). ${ }^{3}$ QCA is a

\footnotetext{
${ }^{2}$ Here, we follow the suggestion of Ingram and Schneider $(1990,522, n .5)$ both conceptually and in the operationalisation presented below. They stated, "most tools can be disaggregated into relatively small units and each unit then scored in terms of all behavioral dimensions of interest to the investigator. Even the smallest units, such as a single statement, may score 'high' on more than one behavioral dimension. The units and their scores can then be reassembled to produce a multivariate characterisation of the original policy tool".

${ }^{3 .}$ QCA is a relatively new research approach (Ragin 1987, 2000, 2008; Rihoux and Ragin 2009; Schneider and Wagemann 2012). In recent years, QCA has drawn increasing attention within the social sciences, and some scholars consider QCA to already be a "mainstream method" in political and sociological research (Rihoux et al. 2013).
} 
configurational and set-theoretic approach in which relationships of necessity and sufficiency are tested and the idea of causality underpinning the approach is fundamentally characterised by equi-finality, ${ }^{4}$ conjunctural causation ${ }^{5}$ and asymmetry. ${ }^{6}$ Therefore, QCA aims at unravelling multicausal rather than mono-causal explanations, focusses on combinations of conditions rather than on single variables, and does not assume that a unique solution (or equation) accounts for both the occurrence and nonoccurrence of a particular outcome.

Furthermore, by applying this method, we can precisely assess which instruments or combinations of instruments are present when better performance is achieved. By using this method of operationalising and methodologically treating policy instruments, a relevant analytical gap can be filled, producing a more precise design for research on the determinants of policy performance; these determinants are too often based on the direct effects of structural and contextual variables (comprising factors such as the socio-economic situation, social capital and the political situation) or processual variables. Overall, policymakers change policy by choosing specific policy instruments, and thus, thanks to the adopted method, it is possible to better describe the content of these decisions. Showing which combinations of instruments are related to specific policy performances plays an enlightening role in readdressing the research on policy evaluation and improving the analysis of the links between policies and outcomes.

\section{Research design}

\section{Case selection and timespan}

This article is based on a specific data set of policy tools used in 12 Western European countries (Austria, Denmark, England, Finland, France, Greece, Ireland, Italy, the Netherlands, Norway, Portugal and Sweden) between 1995 and 2014.

Regarding country selection, we initially intended to cover all the pre-2004 enlargement EU countries. We decided to exclude Eastern European countries due to the period of transition they experienced after 1989, a time of deep turmoil that mixed the communist legacy, the return to precommunist governance and a kind of acceleration towards marketisation (Dobbins and Knill 2009); these characteristics make it quite difficult to assess and code the characteristics of the adopted policy instruments.

However, we were forced to exclude, for different reasons, four additional countries: Luxembourg, due to its small size (one university); Belgium and Germany because of their federal structures and Spain because of its very decentralised regionalism, which has a significant impact on the systemic governance of HE. These 11 pre-2004 enlargement countries reflect all historical types of university

\footnotetext{
${ }^{4}$ The idea of causation in QCA is equi-final in the sense that more than one causal pattern can lead to the outcome (Ragin 1987).

${ }^{5}$ The idea of causation in QCA is characterised by conjunctural causation in the sense that specific combinations of different conditions lead to the outcome (Rihoux and Ragin 2009).

${ }^{6}$ The idea of causation in QCA is asymmetric in the sense that there is no particular relationship between causal patterns leading to the presence of the outcome and the absence of the outcome. Conditions explaining the presence of the outcome are silent with respect to the absence of the outcome, and vice versa (Schneider and Wagemann 2012).
} 
governance that have developed in Europe and can therefore offer sufficient differentiation in terms of policy legacy (Clark 1983; Braun and Merrien 1999; Shattock 2014) and the inherited set of policy instruments. We also included a non-EU country, Norway. Thus, all the Nordic countries, which are assumed to have adopted a welfarist approach to $\mathrm{HE}$, could be considered, and it was possible to examine whether this common characteristic influenced the analysed outcome.

In all the selected countries, the HESs have undergone structural changes in the last two decades. Accordingly, we decided to begin our analysis in approximately the mid-1990s to encompass all the major changes that involved HESs over the last 20 years. ${ }^{7}$ Obviously, each country presents its own reform "starting point" in the field, which means that some of the countries had already produced relevant legislation by the mid-1990s, while others began much later.

\section{Operationalisation}

As already explained in the theoretical section, we assumed that differences in HESs' teaching performance may be associated with - among other things - differences in the combinations of the adopted policy tools. Among the various possible indicators of HESs' performance - such as access, academic recruitment and careers, and third missions - we decided to focus only on teaching, which ultimately represents one of the main tasks of every HE institute. Furthermore, in the last 30 years, all governments have been committed to incentivising universities to pay more attention to the socio-economic needs of their own country and to the need to increase the stock of human capital (currently, in many countries and at the EU level, increasing the number of citizens obtaining a tertiary degree is a major policy goal).

The most common indicator of teaching is the percentage (\%) of people with a university-level degree. ${ }^{8}$ As such, we operationalised teaching performance starting from the percentage of adults between 25 and 34 years old who have a university-level degree. Specifically, because many countries' education systems changed between the 1990 s and the 2000s (possibly because of the Bologna Process), HE programs differ from those that existed 20 years ago. Thus, according to the OECD data, we chose our starting point as the percentage of the 25- to 34-year-old population with a "university-level" education (level 5A in the ISCED 1997 classification) in 1996 compared to the percentage of people of the same age who had either a bachelor's or master's degree in 2015 (levels 6 or 7 in the ISCED 2011 classification). ${ }^{9}$ These data were

\footnotetext{
${ }^{7}$ Some of these reforms were implemented during the 1990s, while many others occurred or developed during the new millennium as a consequence of the Bologna Process.

${ }^{8}$ By "university-level degree", we mean level 5A in the ISCED 1997 classification ("First stage of tertiary education: largely theoretically based programs intended to provide qualifications for gaining entry into more advanced research programs and professions with higher skills requirements") or level 6 (Bachelor's degree or equivalent: "Programs designed to provide intermediate academic and/or professional knowledge, skills and competencies leading to a first tertiary degree or equivalent qualification") or 7 in the ISCED 2011 classification (Master's degree or equivalent: "Programs designed to provide advanced academic and/or professional knowledge, skills and competencies leading to a second tertiary degree or equivalent qualification").

${ }^{9}$ First, we decided to examine the percentage of adults aged 30-34 years who had a university-level degree in each country, as this value was one of the targets of Europe 2020. However, those data account for both university and short-term tertiary degrees, while we coded only regulations related to universities.
} 


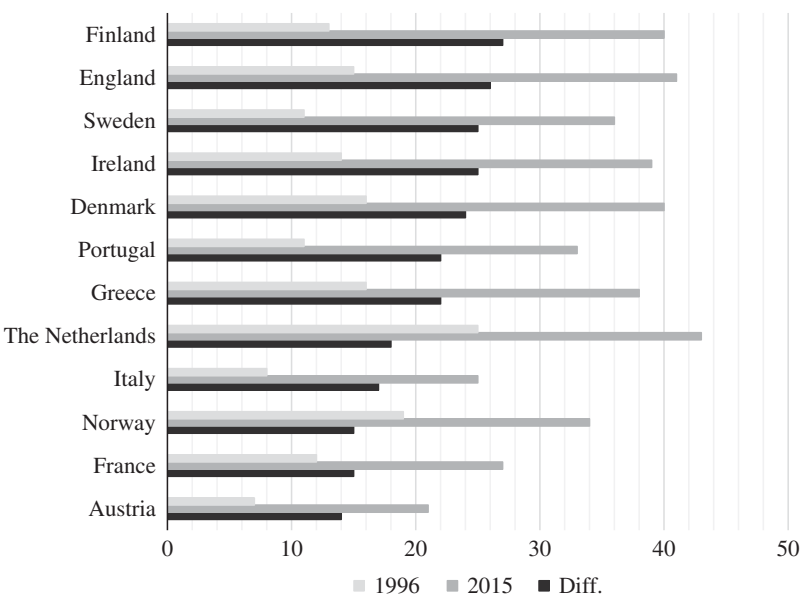

Figure 1. University-level (ISCED 5A 1997 - ISCED 6 + ISCED 7 2011) attainment of 25- to 34-year-old adults: 1996 and 2015 in comparison.

Source: Our elaboration on Organization for Economic Cooperation and Development data.

downloaded from the OECD archive (see also OECD 1998, 2016) ${ }^{10}$ and are summarised in Figure 1.

However, the variation in this performance indicator does not directly represent our outcome because we could not account for two equally relevant considerations: first, improving results is easier when the starting point is a very low value than when it is a higher value, and second, results of university-level education are strongly linked to the structure of tertiary education as a whole. In other words, all else being equal, countries that offer short-cycle tertiary degrees (i.e. first-cycle degrees lasting less than 3 years: level 5B in the ISCED 1997 classification and level 5 in the ISCED 2011 classification) should be rewarded more than countries without them because in the former case, HE institutions are subject to more competition for students (or, at least, they have a smaller catchment area) and, in turn, are less likely to improve their results. Consequently, we modified the data slightly following a two-step process. In the first step, we differentiated countries into three categories: countries below the mean of university degree attainment (25-34 years old) in 1996, countries above the mean but less than 1 Standard Deviation (SD) above the mean, and countries above $1 \mathrm{SD}$ above the mean. Countries in the latter category had an increase in their performance (i.e. in the difference between their level of university degree

\footnotetext{
${ }^{10}$ We opted for a simple indicator of teaching performance because teaching is one of the two main missions of HE, and increasing the number of citizens with an HE degree is a political goal. However, we did not exclude a multidimensional index of performance, as suggested in the literature (Enders et al. 2013), because we are perfectly aware that the concept of "performance" in higher education is very complex and multifaceted (think, e.g. about research performance and the so-called "third mission"). Furthermore, we are also conscious that there is a qualitative dimension of performance, but it is currently virtually impossible to develop a reliable set of comparable data on the "quality dimension". The OECD has launched a research programme on this, but it is still in an initial stage, and the data are not yet very reliable.
} 
attainment in 2015 and in 1996) that was equal to $+50 \%$, whereas countries in the intermediate category (above the mean but less than $1 \mathrm{SD}$ above the mean) had an increase in performance that was between 0 and $+50 \%$, depending on how much they were above the mean. Finally, countries below the mean did not show an increase.

In the second step, we adopted the same differentiation of countries with respect to the ratio between 25- to 34-year-old adults with a short-cycle tertiary degree and those with any tertiary degree in 2015. In this way, we could weigh the extent to which the opportunity to enrol in short-cycle degrees affected the HES as a whole. Again, countries more than $1 \mathrm{SD}$ above the mean had a further increase in their performance that was equal to $+50 \%$, countries above the mean but less than $1 \mathrm{SD}$ above the mean had an increase in performance that was between 0 and $+50 \%$, depending on how far above the mean they were, and countries below the mean did not have an increase. Table 1 presents both the original OECD data and the country rankings based on our measure of teaching performance from 1996 to 2015.

Table 1. Construction of the outcome (teaching performance between 1996 and 2015)

\begin{tabular}{|c|c|c|c|c|c|}
\hline \multirow[t]{15}{*}{ Step 1} & Country & $\begin{array}{c}\text { University } \\
\text { Attainment } \\
\text { (Level 5A)'96 }\end{array}$ & $\begin{array}{c}\text { University } \\
\text { Attainment } \\
\text { (Level 6-7) '15 }\end{array}$ & $\begin{array}{c}\text { Difference } \\
\text { 2015-1996 }\end{array}$ & Increase 1 \\
\hline & Austria & 7 & 21 & +14 & $+0 \%=+0.00$ \\
\hline & Denmark & 16 & 40 & +24 & $+22 \%=+5.33$ \\
\hline & England & 15 & 41 & +26 & $+12 \%=+3.00$ \\
\hline & Finland & 13 & 40 & +27 & $+0 \%=+0.00$ \\
\hline & France & 12 & 27 & +15 & $+0 \%=+0.00$ \\
\hline & Greece & 16 & 38 & +22 & $+22 \%=+4.89$ \\
\hline & Ireland & 14 & 39 & +25 & $+1 \%=+0.21$ \\
\hline & Italy & 8 & 25 & +17 & $+0 \%=+0.00$ \\
\hline & The Netherlands & 25 & 43 & +18 & $+50 \%=+9.00$ \\
\hline & Norway & 19 & 34 & +15 & $+50 \%=+7.50$ \\
\hline & Portugal & 11 & 33 & +22 & $+0 \%=+0.00$ \\
\hline & Sweden & 11 & 36 & +25 & $+0 \%=+0.00$ \\
\hline & Mean & 13.92 & & +20.83 & \\
\hline & SD & 4.68 & & 4.56 & \\
\hline \multirow[t]{15}{*}{ Step 2} & Country & $\begin{array}{l}\text { Short-Cycle } \\
\text { (Level 5) '15 }\end{array}$ & $\begin{array}{c}\text { Tertiary } \\
\text { (Level 5-6-7) } \\
\text { Attainment '15 }\end{array}$ & $\begin{array}{c}\text { Short/Tertiary } \\
(\%)\end{array}$ & Increase 2 \\
\hline & Austria & 16 & 38 & 42.11 & $+50 \%=+7.00$ \\
\hline & Denmark & 4 & 43 & 9.30 & $+0 \%=+0.00$ \\
\hline & England & 8 & 48 & 16.67 & $+3 \%=+0.78$ \\
\hline & Finland & 0 & 41 & 0.00 & $+0 \%=+0.00$ \\
\hline & France & 17 & 44 & 38.64 & $+50 \%=+7.50$ \\
\hline & Greece & 1 & 40 & 2.50 & $+0 \%=+0.00$ \\
\hline & Ireland & 12 & 51 & 23.53 & $+27 \%=+6.75$ \\
\hline & Italy & 0 & 25 & 0.00 & $+0 \%=0.00$ \\
\hline & The Netherlands & 1 & 44 & 2.27 & $+0 \%=0.00$ \\
\hline & Norway & 14 & 48 & 29.17 & $+43 \%=+6.45$ \\
\hline & Portugal & 0 & 33 & 0.00 & $+0 \%=+0.00$ \\
\hline & Sweden & 11 & 45 & 24.44 & $+27 \%=+6.75$ \\
\hline & Mean & & & 15.72 & \\
\hline & SD & & & 14.94 & \\
\hline
\end{tabular}


Table 1. Continued

\begin{tabular}{|c|c|c|c|c|c|}
\hline $\begin{array}{l}\text { Final } \\
\text { outcome }\end{array}$ & Country & $\begin{array}{l}\text { University } \\
\text { Attainment } \\
\text { 2015-1996 }\end{array}$ & Increase 1 & Increase 2 & Final Outcome \\
\hline & Austria & +14 & $+0 \%=+0.00$ & $+50 \%=+7.00$ & +21.00 \\
\hline & Denmark & +24 & $+22 \%=+5.33$ & $+0 \%=+0.00$ & +29.33 \\
\hline & England & +26 & $+12 \%=+3.00$ & $+3 \%=+0.78$ & +29.78 \\
\hline & Finland & +27 & $+0 \%=+0.00$ & $+0 \%=+0.00$ & +27.00 \\
\hline & France & +15 & $+0 \%=+0.00$ & $+50 \%=+7.50$ & +22.50 \\
\hline & Greece & +22 & $+22 \%=+4.89$ & $+0 \%=+0.00$ & +26.89 \\
\hline & Ireland & +25 & $+1 \%=+0.21$ & $+27 \%=+6.75$ & +31.96 \\
\hline & Italy & +17 & $+0 \%=+0.00$ & $+0 \%=0.00$ & +17.00 \\
\hline & The Netherlands & +18 & $+50 \%=+9.00$ & $+0 \%=0.00$ & +27.00 \\
\hline & Norway & +15 & $+50 \%=+7.50$ & $+43 \%=+6.45$ & +28.95 \\
\hline & Portugal & +22 & $+0 \%=+0.00$ & $+0 \%=+0.00$ & +22.00 \\
\hline & Sweden & +25 & $+0 \%=+0.00$ & $+27 \%=+6.75$ & +31.75 \\
\hline & Mean & +20.83 & & & +26.26 \\
\hline & SD & 4.56 & & & 4.46 \\
\hline
\end{tabular}

Source: Our elaboration on Organization for Economic Cooperation and Development data.

The operationalisation of the conditions of the next QCA, namely, the policy instruments, required greater theoretical reflection and greater effort in data gathering, as we will explain below. More precisely, we decided to operationalise the four families of substantial policy tools - regulation, expenditure, taxation and information - while considering a long list of shapes (24 in total), which are presented in Table 2.

Table 2. Classification of policy instruments and their shapes

\begin{tabular}{llll}
\hline Family of Policy & & \\
Instruments & Condition & Shapes & Empirical Examples
\end{tabular}

\begin{tabular}{|c|c|c|c|}
\hline \multirow[t]{5}{*}{ Regulation } & $\mathrm{R} 1$ & $\begin{array}{l}\text { Assessment, } \\
\text { evaluation and } \\
\text { accreditation } \\
\text { (procedural rules) }\end{array}$ & $\begin{array}{l}\text { Austria (1993): University of Applied Sciences Studies } \\
\text { Act: an application for the accreditation of a degree } \\
\text { program as University of Applied Sciences degree } \\
\text { programs had to be addressed to the Agency for } \\
\text { Quality Assurance }\end{array}$ \\
\hline & $\mathrm{R} 2$ & $\begin{array}{l}\text { Agency for } \\
\text { assessment, } \\
\text { evaluation and } \\
\text { accreditation }\end{array}$ & $\begin{array}{l}\text { Denmark (2013): establishment of Danish Agency for } \\
\text { Higher Education as a merger between the Agency } \\
\text { for Higher Education and Educational Support and } \\
\text { the Agency for Universities and Internationalisation }\end{array}$ \\
\hline & R3 & $\begin{array}{l}\text { Content of } \\
\text { curricula: more } \\
\text { constraints }\end{array}$ & $\begin{array}{l}\text { Norway (1995): Act on Universities and University } \\
\text { Colleges: the degree structure, the individual higher } \\
\text { education institution's (HEI) study program } \\
\text { portfolio, and the composition of professional } \\
\text { studies is to be decided on and coordinated at the } \\
\text { national level }\end{array}$ \\
\hline & $\mathrm{R} 4$ & $\begin{array}{l}\text { Content of } \\
\text { curricula: more } \\
\text { opportunities }\end{array}$ & $\begin{array}{l}\text { England (2004): Higher Education Act: the Director } \\
\text { must protect academic freedom, including the } \\
\text { freedom of institutions to determine the contents } \\
\text { and manner of teaching of their courses }\end{array}$ \\
\hline & R5 & $\begin{array}{l}\text { Academic career } \\
\text { and recruitment: } \\
\text { more constraints }\end{array}$ & $\begin{array}{l}\text { Italy (2010): Law 240/2010: can apply calls for } \\
\text { professorial recruitment launched by universities } \\
\text { only if they have obtained a national qualification }\end{array}$ \\
\hline
\end{tabular}


Table 2. Continued

\begin{tabular}{|c|c|c|c|}
\hline $\begin{array}{l}\text { Family of Policy } \\
\text { Instruments }\end{array}$ & Condition & Shapes & Empirical Examples \\
\hline & $\mathrm{R} 6$ & $\begin{array}{l}\text { Academic career } \\
\text { and recruitment: } \\
\text { more } \\
\text { opportunities }\end{array}$ & $\begin{array}{l}\text { France (2013) Decree no. 305/2013: the treatment of } \\
\text { teacher-researcher changes with his career } \\
\text { seniority. Seniority bonuses can be awarded to } \\
\text { lecturers and university professors that are } \\
\text { voluntarily mobile }\end{array}$ \\
\hline & R7 & $\begin{array}{l}\text { Regulation on } \\
\text { students } \\
\text { (admission and } \\
\text { taxation): more } \\
\text { constraints }\end{array}$ & $\begin{array}{l}\text { Greece (1997) Law no. 2525/1997: all upper-secondary } \\
\text { graduates have access to HEls after completing the } \\
\text { Panhellenic University entrance examinations. The } \\
\text { students compete for a fixed number of spaces } \\
\text { irrespective of demand }\end{array}$ \\
\hline & R8 & $\begin{array}{l}\text { Regulation on } \\
\text { students } \\
\text { (admission and } \\
\text { taxation): more } \\
\text { opportunities }\end{array}$ & $\begin{array}{l}\text { Sweden (2012) Prop. 2012/13:1: the university or HEI } \\
\text { decides for themselves the requirement needed to } \\
\text { be accepted to an education, course or program }\end{array}$ \\
\hline & R9 & $\begin{array}{l}\text { Institutional and } \\
\text { administrative } \\
\text { governance: } \\
\text { more constraints }\end{array}$ & $\begin{array}{l}\text { Netherlands (2011) Stb. No. 95/2011: to regulate } \\
\text { accurate decisionmaking with respect to mergers } \\
\text { (fusion), rules were revised. The representative } \\
\text { bodies of the institutions (Councils consisting of } \\
\text { students and staff) must agree with a merger in } \\
\text { advance and must have had the opportunity to } \\
\text { timely assess the effects of the merger ex ante }\end{array}$ \\
\hline & R10 & $\begin{array}{l}\text { Institutional and } \\
\text { administrative } \\
\text { governance: } \\
\text { more } \\
\text { opportunities }\end{array}$ & $\begin{array}{l}\text { Norway (2001) Whitepaper no. } 27 / 2001 \text { : Institutions } \\
\text { were given more freedom in academic, economic } \\
\text { and organisational matters }\end{array}$ \\
\hline & R11 & Contracts & $\begin{array}{l}\text { Austria (2002) Federal Act on the Organisation of } \\
\text { Universities and their Studies: the Federal Minister } \\
\text { shall discuss every } 2 \text { years the total amount } \\
\text { available for the universities - which will then be } \\
\text { split for each university based on the performance } \\
\text { agreements }\end{array}$ \\
\hline & R12 & $\begin{array}{l}\text { Rules on goals in } \\
\text { teaching }\end{array}$ & $\begin{array}{l}\text { Sweden (1993) The Higher Education Ordinance (no. } \\
\text { 100/1993): the government and the parliament } \\
\text { emphasised the need to follow-up educational } \\
\text { outcomes as well as examine and promote quality } \\
\text { enhancement at universities and university colleges }\end{array}$ \\
\hline \multirow[t]{3}{*}{ Expenditure } & E1 & Grants & $\begin{array}{l}\text { Portugal (1997) Lei no. 113/1997: The law also } \\
\text { stipulates the creation of social assistance for } \\
\text { students of a lower socio-economic status, under } \\
\text { the form of grants and other subsidies }\end{array}$ \\
\hline & E2 & $\begin{array}{l}\text { Subsidies and lump- } \\
\text { sum funding }\end{array}$ & $\begin{array}{l}\text { Norway (2001) Whitepaper no. } 27 / 2001 \text { : The reform } \\
\text { changes the funding of HEls. The detailed and } \\
\text { earmarked grants were removed, and HEls' funding } \\
\text { was changed to a lump sum grant at the } \\
\text { institutions' disposal }\end{array}$ \\
\hline & E3 & Targeted funding & $\begin{array}{l}\text { The Netherlands (2010) Stb. No. 166/2010: the } \\
\text { ministry introduces the so-called Sirius program, } \\
\text { i.e. funding bachelors or masters programs of } \\
\text { universities and UAS (in competition) focussed } \\
\text { towards excellence }\end{array}$ \\
\hline
\end{tabular}


Table 2. Continued

Family of Policy

Instruments Condition Shapes Empirical Examples

E4 Loans

Denmark (1994) Amendment of Act relating to

educational support: the act introduces a loan

given to students who have used up the "punches"

in their klippekort (a system similar to travel cards

or season tickets that are punched for each use).

These students are now given an additional loan in

the last year of their education (SU-loven, 1994).

The loan was intended to help these students finish their studies

E5 Performance-based

Austria (2014) UG 02 as of 2014 amendment: institutional funding structural funds are appointed to individual universities and are calculated in accordance with qualitative, quantitative and performance-based indicators

E6 Standard cost per

Ireland (2013) Higher Education System Performance student Framework: the annual core grant is allocated as a block grant - based on a formula with a standard per capita amount

Taxation T1 Tax exemption

Portugal (1992) Lei no. 20/1992: it stipulates that lowincome students (based on a threshold which was to be defined each year by the Ministry of Finance) would be exempt from the tuition fee or receive a discount

T2 Tax reduction for particular categories of students student fees

Austria (2008) Decree no. 134/2008: Remission or Reimbursement of study fees extended for $50 \%$ of disabled or pregnant students or self-employed or working students

Portugal (2003) Lei n.o 37 de 22 de Agosto - Tuition fees are changed and are no longer a flat rate across all universities. Instead, they vary depending on the institution, the courses, and the relative quality

Information I1 Transparency

England (1988) Education Reform Act: a higher education corporation shall have power to publish the results of the research or any other material arising out of or connected with it

12 Certifications

Sweden (2011) Prop. no. 133/2011: the operations that were managed by UHR are ... assessment of foreign diplomas ...

13 Monitoring and reporting

Ireland (2003) Official Languages Act: the Act specifies that each university must generate regular reports and other documents such as a strategic plan, quality assurance reports (s 35), an equality policy (s 36) and various financial reports (ss 37-42)

In this way, we tried to capture all the possible shapes that substantial HE policy instruments can take. We also avoided constructing categories that were too exclusive, which would have made the data collected in different countries difficult to compare.

Finally, it is important to note that there is a one-year lag between conditions and the outcome: conditions are operationalised based on data from 1995 to 2014, while the outcome compares (adjusted) teaching performance in 1996 and 2015. 
The reason is that we believe that most changes in the policy instruments could have a "quasi-immediate" impact on behaviours, and a one-year time lag carefully takes this process into account. ${ }^{11}$

\section{Data collection, data set construction and coding}

By following the lines of our theoretical framework - which focussed on the different combinations of the existing set of adopted policy combinations - we collected, analysed and coded all pieces of national legislation and regulations regarding $\mathrm{HE}$ in all 12 countries under analysis from the mid-1990s onwards. Hundreds of official documents and thousands of pages of national legislation were carefully scrutinised and hand-coded in the search for both substantial and procedural policy instruments. The coding procedure proceeded in three steps: first, we identified a list of relevant pieces of legislation in national HE policy, namely, laws, decrees, circulars and ministerial regulations that affected the HES of each country under scrutiny. Second, we reduced every piece of legislation to its main issues. Third, we attributed each of those issues to one of the shapes in which we classified the policy instrument repertoire in HE.

For the first two steps, the research strategy was twofold. With respect to Italy, France and both English-speaking countries - England and Ireland - the analysis was conducted "in house", meaning that the three authors of this article were responsible for entering the Italian, French, English and Irish pieces of legislation into the data set. Linguistic barriers rendered the selection of regulations and their direct coding impossible for the other eight countries - Austria, Denmark, Finland, Greece, the Netherlands, Norway, Portugal and Sweden. Therefore, we contacted a highly reputable country expert for each case to achieve a perfectly comparable list of pieces of relevant regulation and, in turn, legislative provisions regarding HE for those countries.

The attribution of all the analysed relevant decisions to the appropriate categories (substantial policy instruments and related shapes) was again conducted by the authors. This final step of the coding procedure was developed as follows: first, each issue of each legislative provision in each country was coded separately by each author; second, contradictory cases - that is policy instruments placed in different categories by two or more coders (approximately 15\% of the whole sample) - were solved jointly in a subsequent stage.

\section{Linking policy instruments with teaching performance in Western Europe Policy mixes in Western European HESs: an overview of the adopted policy shapes}

While we refer to the Online Supplementary Material (Appendix A) for all technical details concerning our QCA, we first would like to provide a general picture

\footnotetext{
${ }^{11}$ We are aware that it can also be argued that policy changes in the area of HE do not have almostimmediate effects. The immediacy of effects clearly depends on the type of policy change, and some policy changes may require more time than others to produce effects (while a change in tuition fees or in the formula funding can have an immediate effect, a change in institutional governance can require several more years to show an impact). To account for this consideration, we conducted a robustness check with a 5 -year time lag between policy instruments and the outcome (see the Online Supplementary Material). The results were not particularly different from those when we hypothesised an almost-immediate effect.
} 
Table 3. Higher education systems' governance reforms in Western Europe (1995-2014)

\begin{tabular}{lccccccccccccc}
\hline & $\mathrm{A}$ & $\mathrm{D}$ & $\mathrm{E}$ & $\mathrm{FI}$ & $\mathrm{FR}$ & $\mathrm{G}$ & $\mathrm{IR}$ & $\mathrm{IT}$ & $\mathrm{NE}$ & $\mathrm{NO}$ & $\mathrm{P}$ & $\mathrm{S}$ & Tot \\
\hline R1 & 3 & 4 & 1 & 4 & 9 & 3 & 9 & 14 & 4 & 16 & 8 & 5 & 80 \\
R2 & 2 & 4 & 0 & 0 & 3 & 4 & 3 & 2 & 1 & 3 & 2 & 3 & 27 \\
R3 & 1 & 2 & 1 & 6 & 4 & 5 & 0 & 4 & 4 & 3 & 0 & 5 & 35 \\
R4 & 5 & 12 & 1 & 2 & 6 & 7 & 0 & 3 & 6 & 6 & 2 & 8 & 58 \\
R5 & 0 & 0 & 1 & 1 & 2 & 3 & 2 & 6 & 0 & 1 & 3 & 1 & 20 \\
R6 & 1 & 0 & 1 & 1 & 4 & 3 & 5 & 6 & 1 & 0 & 4 & 1 & 27 \\
R7 & 3 & 2 & 1 & 0 & 1 & 1 & 1 & 0 & 7 & 3 & 0 & 3 & 22 \\
R8 & 6 & 4 & 4 & 11 & 3 & 3 & 0 & 1 & 6 & 3 & 0 & 5 & 46 \\
R9 & 1 & 3 & 4 & 8 & 6 & 7 & 8 & 6 & 3 & 2 & 1 & 2 & 51 \\
R10 & 4 & 11 & 0 & 6 & 6 & 7 & 3 & 2 & 7 & 14 & 4 & 3 & 67 \\
R11 & 4 & 2 & 1 & 0 & 2 & 1 & 1 & 1 & 0 & 1 & 0 & 0 & 13 \\
R12 & 1 & 3 & 0 & 4 & 1 & 1 & 0 & 2 & 3 & 4 & 0 & 4 & 23 \\
N Reg. & 31 & 47 & 15 & 43 & 47 & 45 & 32 & 47 & 42 & 56 & 24 & 40 & 469 \\
\% Reg. & 57.4 & 67.1 & 50.0 & 53.8 & 70.1 & 68.2 & 62.7 & 58.0 & 70.0 & 60.2 & 64.9 & 74.1 & 63.1 \\
E1 & 2 & 3 & 1 & 4 & 2 & 3 & 0 & 2 & 5 & 5 & 4 & 3 & 34 \\
E2 & 3 & 1 & 0 & 7 & 2 & 5 & 1 & 1 & 2 & 3 & 1 & 2 & 28 \\
E3 & 1 & 7 & 0 & 8 & 4 & 2 & 2 & 1 & 2 & 2 & 0 & 2 & 31 \\
E4 & 1 & 2 & 2 & 0 & 1 & 2 & 0 & 2 & 4 & 4 & 1 & 2 & 21 \\
E5 & 1 & 1 & 4 & 8 & 2 & 3 & 4 & 5 & 0 & 10 & 2 & 0 & 40 \\
E6 & 1 & 1 & 0 & 2 & 0 & 0 & 1 & 2 & 0 & 1 & 0 & 0 & 8 \\
N Exp. & 9 & 15 & 7 & 29 & 11 & 15 & 8 & 13 & 13 & 25 & 8 & 9 & 162 \\
\% Exp. & 16.7 & 21.4 & 23.3 & 36.3 & 16.4 & 22.7 & 15.7 & 16.0 & 21.7 & 26.9 & 21.6 & 16.7 & 21.8 \\
T1 & 2 & 1 & 0 & 1 & 1 & 0 & 1 & 1 & 0 & 0 & 0 & 0 & 7 \\
T2 & 2 & 0 & 5 & 1 & 3 & 0 & 3 & 4 & 1 & 0 & 0 & 0 & 19 \\
T3 & 0 & 0 & 0 & 2 & 0 & 0 & 0 & 1 & 0 & 2 & 3 & 0 & 8 \\
N Tax. & 4 & 1 & 5 & 4 & 4 & 0 & 4 & 6 & 1 & 2 & 3 & 0 & 34 \\
\% Tax. & 7.4 & 1.4 & 16.7 & 5.0 & 6.0 & 0.0 & 7.8 & 7.4 & 1.7 & 2.2 & 8.1 & 0.0 & 4.6 \\
I1 & 3 & 4 & 2 & 2 & 3 & 4 & 5 & 10 & 3 & 6 & 1 & 0 & 43 \\
I2 & 1 & 0 & 1 & 1 & 1 & 0 & 0 & 0 & 0 & 1 & 0 & 3 & 8 \\
I3 & 6 & 3 & 0 & 1 & 1 & 2 & 2 & 5 & 1 & 3 & 1 & 2 & 27 \\
N Info. & 10 & 7 & 3 & 4 & 5 & 6 & 7 & 15 & 4 & 10 & 2 & 5 & 78 \\
\% Info. & 18.5 & 10.0 & 10.0 & 5.0 & 7.5 & 9.1 & 13.7 & 18.5 & 6.7 & 10.8 & 5.4 & 9.3 & 10.5 \\
Tot & 54 & 70 & 30 & 80 & 67 & 66 & 51 & 81 & 60 & 93 & 37 & 54 & 743 \\
\hline & & & & & & & & & & & & &
\end{tabular}

of how the countries under scrutiny intervened in HE between 1995 and 2014. More precisely, Table 3 indicates how often each country in our sample recurred to all the shapes of policy instruments listed in Table 2.

With regard to regulation - the most utilised family of policy instruments Figure 2 reveals that two out of the three most adopted instrumental shapes are concerned with giving more opportunities to universities in terms of both the content of curricula and the institutional governance (which seems quite coherent with the common template pursued by all the examined countries: the "steering at a distance" governance model). However, the most frequently utilised of all the policy instruments is related to assessment, evaluation and accreditation, which proves, from a quantitative point of view, what has been repeatedly argued qualitatively in the literature, namely, that Western European countries largely utilised evaluation tools over the course of the last 20 years (Neave 2012; Rosa and Amaral 2014).

Figure 3 indicates which shapes were the most frequently used over the other three families of substantial instruments. Apparently, this general picture also 


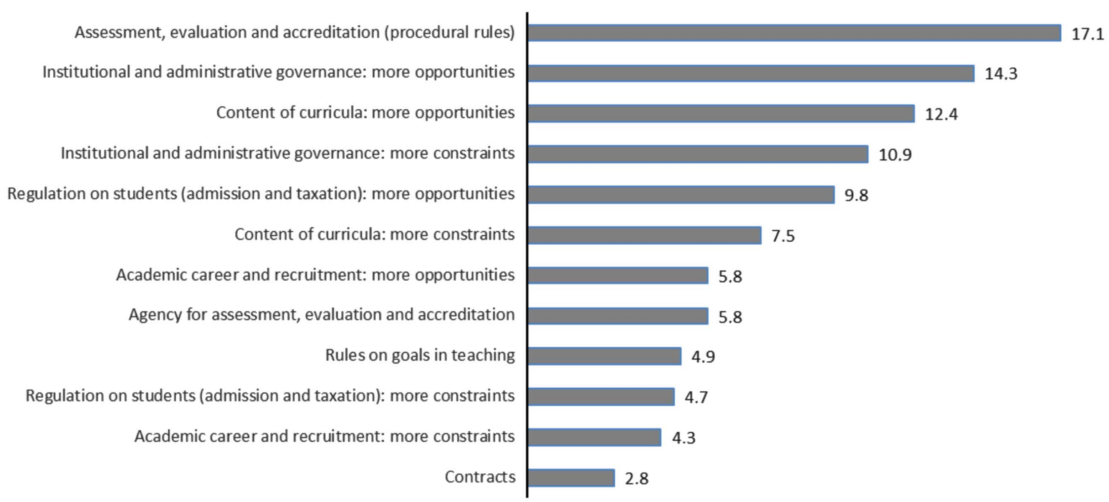

Figure 2. Regulation: Which instruments are utilised the most (\%)?

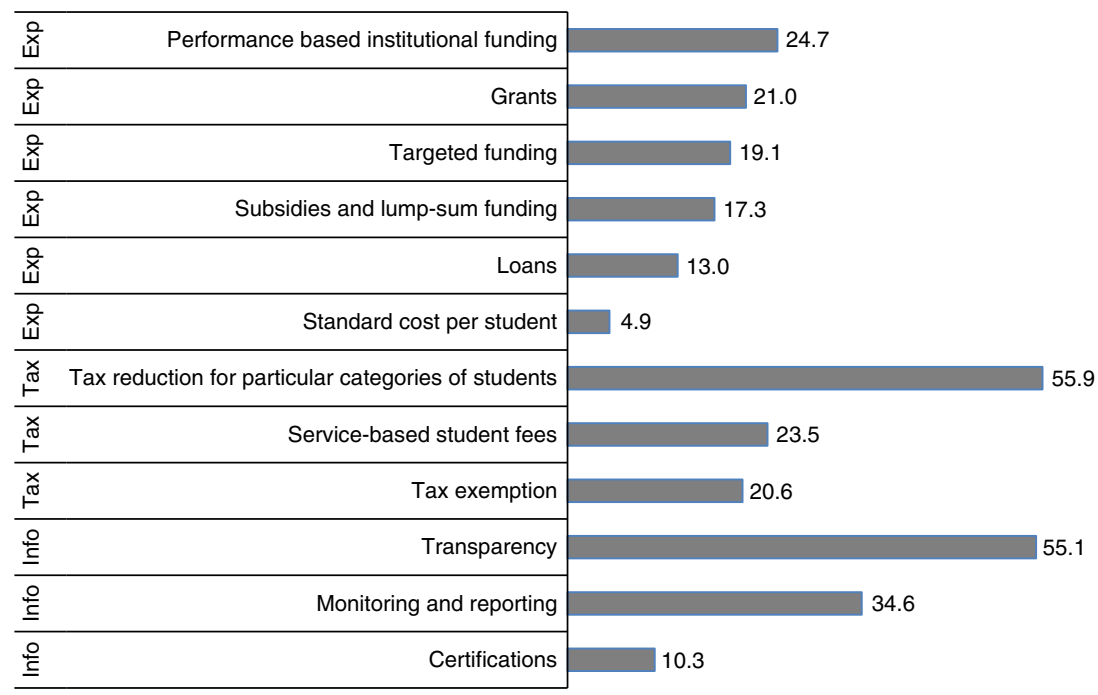

Figure 3. Other families of substantial policy tools (expenditure, taxation and information): Which instruments are utilised the most (\%)?

confirms the trend towards a common template, but with some relevant specifications.

In fact, expenditure was delivered not only through grants but also through targeted funding and, above all, through performance-based institutional funding. Thus, the most expected expenditure instrument in a pure "steering at a distance" governance model - lump sum - was adopted less frequently than expected. Therefore, governments preferred a more coercive way to allocate public funding (together with an emerging attitude favouring the inclusion of families in paying HE loans) and thus demonstrated the will to maintain a certain degree of control over the behaviour of universities. 
Finally, regarding both taxation and information, it emerged that two instrumental shapes were particularly utilised: tax reduction for particular categories of students and transparency.

\section{What can be associated with better teaching performance? A configurational analysis}

We return to fuzzy-set QCA (fs-QCA) ${ }^{12}$ to empirically explore the combinations of policy instruments and related shapes that might contribute to explaining teaching performance in Western European HESs between 1996 and 2015. While we refer to the Online Supplementary Material (Appendix A) for a careful discussion and justification of the thresholds chosen in the process of "calibrating" the sets (both the conditions and the outcome) (Ragin 2008; Schneider and Wagemann 2012), this section presents the main results of our empirical analysis in terms of both the need for and sufficiency of relations between conditions, that is instrumental shapes, and the outcome, namely (adjusted) teaching performance.

The analysis of necessary conditions for improving teaching performance was completed quickly: no condition (or its nonoccurrence) was necessary for the outcome (or for its nonoccurrence). ${ }^{13}$ In other words, we could not identify any conditions that needed to be present or absent to observe either a good teaching performance (presence of the outcome) or a bad teaching performance (absence of the outcome) between 1996 and 2015.

However, much more interesting is the analysis of the sufficient conditions for improving teaching performance in HE, which was conducted with a "truth table". It clearly would not have been feasible to perform an analysis of sufficiency on 12 cases with dozens of different conditions (i.e. instrumental shapes) due to problems of limited diversity of the data (Schneider and Wagemann 2012; Vis 2012); thus, we turned to theoretical reflections to hypothesise a set of possible combinations to be tested in our fs-QCA.

First, we began with 45 theoretically relevant potential configurations of conditions that populated the literature on HES performance. These combinations of instrumental shapes build mainly on the literature emphasising the adoption of similar policy instruments to follow the common template of the "steering at a distance" model. The combinations also build on the empirical evidence and contradictions emerging from variable-oriented studies that focussed on the determinants of performance in HE. Regarding the "steering at a distance" literature, we have already emphasised the substantial literature underlying the ways governments have been changing governance in HE by improving institutional autonomy (and its dimensions, such as budgetary autonomy, degree of freedom in curricular content and autonomy in recruiting academic staff), quality assurance, accreditation, teaching and research assessments, monitoring, and varieties of funding mechanisms (Gornitzka et al. 2005; Cheps 2006; Lazzaretti and Tavoletti 2006; Maassen and Olsen 2007; Trakman 2008; Huisman 2009, Shattock 2014, Capano et al. 2016).

\footnotetext{
${ }^{12}$ We used the fs-QCA software downloaded from the website of Charles Ragin.

${ }^{13 .}$ All the consistency thresholds were lower than 0.9 , which is the value above which empirical evidence supports the claim that a condition is necessary for the outcome (Schneider and Wagemann 2012, 278). See Appendix A for details.
} 
This literature clearly addressed our choice to consider the shapes for each family of substantial policy instruments that seemed to best represent the operative dimensions of the main categories of government intervention. This choice was reinforced by the contributions that focussed on the real effects of performancebased funding on institutional autonomy and on the degree of centralisation of the governance system. This literature produced contrasting empirical evidence and thus suggested a strategic dimension that we should take into consideration. For example, with respect to performance and targeted funding as a cause of high graduation and research rates, the relevant studies showed the weak performative capacity of these instruments. Most of these studies focussed on the United States (US), where many states introduced performance criteria to determine the allocation of extra resources beginning at the end of the 1970s (Volkwein and Tandberg 2008; Rabovsky 2012; Rutherford and Rabovsky 2014; Tandberg and Hillman 2014). This evidence was quite contradictory compared to the widespread use of these types of instruments by the governments of our analysed countries. Thus, we considered all targeted expenditure tools as relevant in our combinations.

Regarding institutional autonomy, contradictory evidence has emerged from reputable studies. For example, in their comparison between the EU and the US, Aghion et al. (2010) found that high institutional autonomy (and a competitive environment) was positively correlated with high performance both in educational attainment and in research. By contrast, Braga et al. (2013) showed that high institutional autonomy negatively impacted the level of educational attainment.

With respect to the level of the centralisation of the governance system, Knott and Payne (2004) considered systemic centralisation in US states to be high, intermediate, or low depending on the scope of the decision-making powers held by state boards. They tested systemic centralisation as a condition affecting an array of resource and productivity measures, including the size of university revenue and the number of published articles. They concluded that state governance matters and that flagship universities are penalised by centralisation, which reduces their total revenues, research funding and number of published articles. However, centralisation was also found to reduce tuition revenues and - presumably - the cost of enrolment. The worst overall performance occurs under mild centralisation. However, this interpretation contrasts with a qualitative study of five US states conducted by Richardson and Martinez (2009). They argued that universities in centralised systems might perform better than those with decentralised designs with respect to access and graduation rates.

Thus, according to the literature, and assuming that governments have tried to pursue the "steering at a distance" model in accordance with their own national identity, we attempted to combine these shapes in such a way that 45 different policy mixes - 30 consisting of four instrumental shapes belonging to different families of instruments and 15 consisting of five of those same instrumental shapes - were established (see Table A4 in the Online Supplementary Material for those 45 different policy mixes).

Then, we performed 45 different QCAs - one for each of the selected policy mixes - to ascertain the combination of conditions that were more theoretically convincing and empirically robust. To accomplish this, we followed a two-step process. First, we focussed on the values of consistency and the coverage of different (intermediate) final solutions. In fact, in the QCA literature, it is generally argued that "coefficients of consistency and coverage provide important numeric 
expressions for how well the logical statement contained in the QCA solution term fits the underlying empirical evidence and how much it can explain" (Schneider and Wagemann 2010, 414). Therefore, scholars have reviewed the coefficients to measure the goodness of fit of the tested theoretical models (Ragin 2006). This first step allowed us to realise that two combinations existed with both consistency and coverage values that were much higher than any other, as well as higher (or, at least, equal to) than 0.90 , which is a notable value. ${ }^{14}$ However, limiting our comparison to consistency and coverage alone would be insufficient (Braumoeller 2015; Rohlfing 2018); it is important to also account for the theoretical plausibility of solutions and the (groups of) countries that are identified by each solution term. For this reason, in our second step, we carefully scrutinised those same two combinations of instrumental shapes, looking for results that appeared to be more theoretically plausible and empirically grounded. In applying these further selection criteria, we realised that one combination was preferable to the other. ${ }^{15}$

Thus, at the end of the above-described analytical process, the best combination of instrumental shapes that emerged from the QCA for explaining the teaching performance of the analysed sample of countries between 1996 and 2015 consisted of R1 (assessment, evaluation and accreditation); R10 (institutional and administrative governance: more opportunities); R12 (rules on goals in teaching); E5 (performance-based institutional funding); and T3 (service-based student fees) (Table 4).

Table 4. Explaining teaching performance: the best policy mix (intermediate solution)

\begin{tabular}{lcccc}
\hline $\begin{array}{l}\text { Solution } \\
\text { terms }\end{array}$ & $\begin{array}{c}\text { Raw } \\
\text { coverage }\end{array}$ & $\begin{array}{c}\text { Unique } \\
\text { coverage }\end{array}$ & Consistency & Cases covered \\
\hline R12 & 0.62 & 0.52 & 0.88 & Den $(0.73,0.93) ;$ Fin $(0.95,0.77) ;$ Ned $(0.73,0.77) ;$ Nor \\
E5* $\sim$ T3 & 0.39 & 0.29 & 0.91 & Eng $(0.86,0.95) ;$ Gre $(0.65,0.76) ;$ Ire $(0.86,0.98)$ \\
\hline
\end{tabular}

Note: Solution coverage (proportion of membership explained by all paths identified): 0.908847 .

Solution consistency ("how closely a perfect subset relation is approximated") (Ragin 2008, 44): 0.895641.

Raw coverage: proportion of memberships in the outcome explained by a single path.

Unique coverage: "proportion of memberships in the outcome explained solely by each individual solution term" (Ragin 2008, 86).

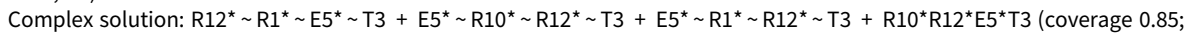
consistency 0.95).

Parsimonious solution: $\mathrm{R} 12+\mathrm{R} 10^{\star} \sim \mathrm{R} 1+\mathrm{E}^{*} \sim \mathrm{T} 3+\mathrm{T} 3^{\star} \sim \mathrm{R} 1+\mathrm{R} 10^{\star} \mathrm{T} 3+\mathrm{R} 1^{\star} \sim \mathrm{R} 10^{\star} \sim \mathrm{T} 3$ (coverage 0.95 ; consistency 0.85).

The consistency value of the intermediate solution was impressive (0.90), and the coverage of the (intermediate) solution formula was even better (0.91). There was no "deviant case for coverage" (Schneider and Rohlfing 2013, 585). As shown

\footnotetext{
14. These combinations were "Combination 32" and "Combination 45". For details about all configurations of conditions, see the Online Supplementary Material.

${ }^{15}$ For example, the third solution term of the (intermediate) final solution characterising the "Combination 32" consisted of three absences of instrumental shapes: it was the conjunct absence of R1 (Assessment, evaluation and accreditation), E6 (Standard cost per student) and T3 (Service-based student fees) that was associated with good teaching performance in England and Sweden. However, explaining the presence of the outcome with only absences of instrumental shapes appears to be fairly unsatisfactory: it seems that some factor remained out of the picture.
} 
in Figure 4, six cases (i.e. Denmark, England, Greece, Ireland, the Netherlands and Sweden) were above the diagonal in the upper-right corner - and thus were "typical cases" - whereas two cases (i.e. Finland and Norway) were "deviant cases in consistency of degree". Finally, the four cases (namely, Austria, France, Italy and Portugal) in the lower-left quadrant - being a good example of neither the solution terms nor the outcome - did not merit particular attention.

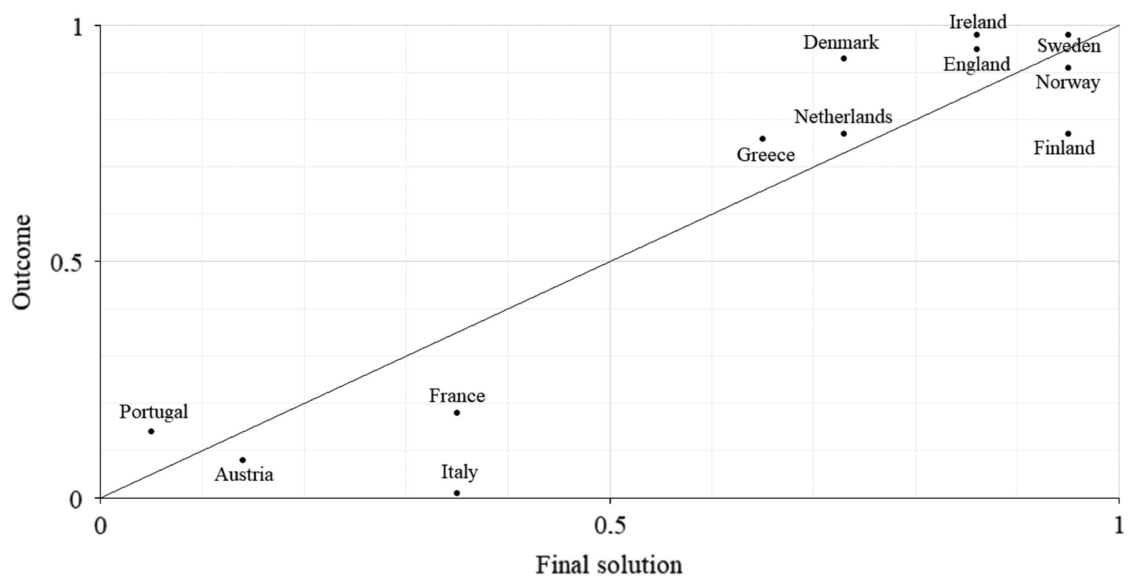

Figure 4. The "best policy mix": final $X Y$ plot.

The above analysis of policy mixes thus means that in our sample of countries, it was possible to identify two distinct paths associated with an increase in teaching performance. First, in the Scandinavian countries - Denmark, Finland, Norway and Sweden - together with the Netherlands, it emerged that the rules on systemic goals in teaching were the prevailing policy instrument, which clearly indicates the aims to be achieved by institutions. Second, in the Anglo-Saxon countries England and Ireland - together with Greece, improved performance was associated with performance-based institutional funding; moreover, those three countries were also similar in that they did not pay very much attention to service-based student fees.

\section{Discussion of the findings}

This analysis showed how instrumental shapes were composed in the 12 analysed countries, and we also treated these mixes with fs-QCA to assess which combinations of instrumental shapes were associated with better systemic performance in teaching. The empirical evidence is quite promising in both areas.

Regarding the composition of the national packages of instrumental shapes, the different distributions of substantial instruments and their possible shapes revealed that there was significant variance when mixing the same substantial instruments and their shapes. This variance, of course, calls for a better understanding of which combination(s) of instrumental shapes can be associated with better HES performance in terms of teaching. Thus, this emerging variance in the composition of policy mixes incontrovertibly shows how the common template, the "steering at a distance" mode 
of governing HESs, was applied in a very loose way, that is, as a generic framework that each country interpreted in a very specific and idiosyncratic way.

The findings emerging from our QCA treatment are relevant with respect to both the specific issue of identifying the most effective policy mixes in governing HESs and the more general theoretical and empirical problem of operationalising governance shifts and their potential policy effectiveness.

The first issue is that among the eight cases showing the outcome, there is a clearcut divide based on the presence of only one condition (instrumental shape). On one hand, there are countries in which the performance funding shape prevails, and thus, the government "steers at a distance" by financially addressing the behaviour of the institution. This is the case for England, Greece and Ireland, where the conjunction between performance funding and the absence of service-based student fees is sufficient for the outcome. Here, it is surprising that this solution term groups together countries belonging to different traditions in governing $\mathrm{HE}$.

On the other hand, the four Nordic countries plus the Netherlands are clustered together by the presence of a significant governmental role in indicating the systemic goals to be achieved, which is a sufficient condition for the outcome. In these countries, the government has significantly followed an autonomistic policy but has counterbalanced it through a clear indication of what the overall system is expected to deliver in terms of teaching performance.

This clear-cut result raises a relevant issue because it shows how the mix of instrumental shapes makes a difference regardless of the "quantity" of shapes of the same family of substantial instruments that has been introduced. For example, in the Greek case, the association of performance funding with the outcome occurs in the presence of a high percentage of adopted regulatory instrumental shapes, while in the Norwegian and Finnish cases, the impact of a specific regulatory shape (R12, rules on goals in teaching) appears more relevant with respect to expenditure shapes, notwithstanding the finding that these two Nordic countries scored first in terms of the percentage of adoption of expenditure instrumental shapes.

This evidence raises a more general consideration that emerges from our analysis: the fact that each solution term highlights the relevance of the presence of only one instrumental shape. This finding suggests taking into consideration the hypothesis that some specific shapes of policy instruments make a difference regardless of the other shapes of policy instruments with which they work. This empirical evidence could appear simply because we chose only the most frequently adopted instruments according to the specialised literature or because the final results show the cumulative effect of different compositions of policy mixes adopted over time. However, the hypothesis that a small combination of instruments can make a significant difference irrespective of the other instruments that can be part of the actual adopted policy mix also deserves more empirical attention because - if confirmed - it could have a relevant impact on the actual trend in the literature on policy instruments and on policy performance. Obviously, this evidence could depend on different contexts and on different implementation practices (in terms of policy instruments, this means primarily the rules and organisational procedures through which instrumental shapes are implemented); it could also depend on a specific temporal sequence of adoption of policy instruments (e.g. the relevance of both systemic goals and performance funding could require the presence of significant and effective previously adopted institutional autonomy on curricula and recruitment at work). However, while accepting this 
consideration, the emergence of the hypothesis that only a small number of instrumental shapes - or even only one shape, regardless of the other adopted shapes - can be associated with the presence of a performance improvement also appears intriguing and promising.

\section{Conclusions and future research}

We devoted this article to addressing a general problem in analysing governance shifts in public policy by empirically focusing on HE as an exemplary field. We assumed that the complexity of understanding whether and how governance changes should be analysed from a detailed perspective that begins from the basic component of governmental actions and governance arrangements: policy instruments. We proposed a classification of substantial instruments (regulation, expenditure, taxation and information) to grasp the complete spectrum of induced behaviour that can be addressed. Then, we operationalised these substantial instruments according to 24 different shapes. We used this long list to code the instrumental choices made in 12 European countries over the last 20 years in their HES governance arrangements. Afterwards, we developed a fs-QCA to assess which combination of instrumental shapes is associated with good systemic performance in teaching, operationalised by taking into account the (adjusted) increase in the percentage of 25- to 34-year-old adults with a university-level degree. The empirical analysis allowed us to identify the most theoretically convincing and empirically robust combination of instrumental shapes associated with the teaching performance of the analysed countries between 1996 and 2015. In more detail, it was possible to identify two distinct paths associated with the outcome: while in the Scandinavian countries and the Netherlands, rules on goals in teaching were the prevailing policy instrument, in Anglo-Saxon countries and Greece, good teaching performance was associated mainly with the presence of performancebased institutional funding, together with the absence of service-based student fees.

Of course, we are aware of the intrinsic limitations of our research design: first, the link between policy instruments and teaching performance is indirect; second, policy performance is driven by many factors that interact with the adopted instrumental shapes, and we were not able to assess the role of external factors ex ante. For example, expenditure instrumental shapes may have a different impact on teaching performance depending on whether a drastic reduction in public funding is occurring concomitantly; a peak in enrolment can increase the opportunity to produce more graduates, especially if this figure is linked to an increase in assigned grants; or an increase in institutional autonomy (and thus of greater competition among universities in their teaching offerings) may have different effects according to the general socio-economic situation of the country; and similar considerations can be drawn with regard to many more instrumental shapes.

Nonetheless, we are convinced that policy instruments can be intended as possible explanatory conditions (among others) and thus that a specific focus on them is absolutely needed to better understand and order what really occurs when governments decide to intervene in a policy field with the only means they have at disposal: by choosing specific instrumental shapes or combinations of them. Accordingly, the results of our exploration are quite interesting both for the study of performance in HE and, more generally, for the study of the effects of governance shifts in public policy and, in turn, with regard to the portfolios/mix of adopted policy instruments. 
With regard to the literature evaluating the performance of university systems, our empirical evidence shows that the same outcome is associated with a specific configuration of conditions (shapes of policy instruments) that must be present or absent to work. This way of thinking and, thus, this reading of the way governance arrangements work is explained by different combinations of instrumental shapes that can be associated with similar effects and, thus, by the way these combinations should be properly contextualised. In this sense, the empirical evidence presented in this article shows that the evaluative literature on HE performance should find a third method that lies between the variable-oriented research strategy and the dense description of case-study analysis to fully grasp what may be important in terms of performance.

Furthermore, with respect to the literature on $\mathrm{HE}$ focussing on the bundle of changes that have been discussed from a comparative perspective towards a common template - the "steering at a distance" model - there have clearly been certain national paths that have merged when translating the common template focussed on certain instruments over others. Why these paths, these specific combinations of instruments, have been chosen is not of interest in this article, but it could be taken into consideration in the future for a better understanding and explanation of the process of governance shifts, their features, their drivers and their decisional outputs.

Finally, regarding the broader literature on policy instrument mixes, this article proposes a research design through which it is possible to overcome its actual limitations and thus a new way towards: (1) how to conceptualise and operationalise policy instruments to reach a better description of both the content of policy mixes, as well as (2) how they really work in terms of performance.

Regarding the content of policy mixes, we have shown how reasoning in terms of instrumental shapes can be useful for better grasping the multidimensionality of policy instruments. According to this way of operationalising policy instruments, a more detailed picture of real adopted policy instruments can be obtained; thus, more fine-grained analyses, including analyses in comparative terms, are possible. This evidence calls for the suggestion of Ingram and Schneider (1990) and Salamon (2002) to be taken seriously: to grasp the real composition of policy mixes (and of their potential effects). The various types of policy instruments should be disaggregated into smaller units, and thus, the shapes through which policy instruments are actually adopted when decisionmakers design policies should be designed.

Regarding the functioning of policy mixes with respect to policy performance, this article has shown (or, at least, has raised the intriguing hypothesis) that often, only a limited combination of instrumental shapes may truly be associated with the outcome of interest, despite the larger number of instrumental shapes that compose the adopted policy mix. Thus, it could be that only a few instrumental shapes can make a difference, regardless of the more articulated composition of the actual policy mix.

We are perfectly aware that another limitation of our analysis is that we did not consider the institutional "impact" of instruments (or the content of the implementation process, where different institutional interpretations and strategies can be at work), but we were unable to do this because the analytical focus was on policy design and thus on the formal decisions made at the national level. Although we have focused on a specific dimension of policy instrument mixes, we believe that this could be a first necessary step towards a deeper analysis in terms of changes obtained over time. Overall, the way decisionmakers design policies by arranging different instrumental shapes should matter. 
There are obviously different possible paths for further research starting from the approach we have presented in this article. We describe four of them here.

The first path would be to extend the research while including countries belonging to different geo-political contexts and with different legacies in governing HESs and, more ambitiously, to broaden the scope of the research by including and comparing different policy fields. This extension could also allow us to test whether there could be a way to find a list of instrumental shapes that have an intersectorial analytical use.

The second path would be to deepen the analysis in order to investigate the working rules of the shapes through which the substantial instruments are used (implementation practices). This step would also mean working on the dimensions of the rules through which each shape is designed. We refer to the rules through which decisional powers and competences are attributed; accountability rules are fixed when the shapes are designed. For example, regarding the use of performance funding, the focus should be on the percentage of public funding allocated, the criteria for allocating performance funding, the means and timing of evaluation and so on. Obviously, this path would be very complex, but it could be a very interesting and promising way to definitively elucidate how instruments work in day-to-day policy dynamics.

The third path would be to focus on a few exemplary national cases for a deeper analysis of the diachronic sequence of instrumental choices made by governments and of their cumulative effects in terms of association with performance. This analytical deepening could allow us to clarify whether some instrumental shapes matter more than others or whether this step is simply the final emergence of a specific sequence of instrumental choices.

The fourth path would be an analysis of the diachronic interaction between structural/environmental factors and policy mixes in determining the policy performance to better assess the "association" (and maybe to upgrade it to the "explanatory" level) between some instrumental shapes and improved performance that we found in our research.

We are definitively convinced that policy instruments matter, and in the future, more empirical work should be done to better understand how these instruments do their job.

Supplementary material. To view supplementary material for this article, please visit https://doi.org/ $10.1017 /$ S0143814X19000047

Data Availability Statement. This study does not employ statistical methods and no replication materials are available.

Acknowledgement. The research content presented in this article was made possible by a grant of the Italian Ministry of Education (PRIN 2015). We thank three anonymous referees for their helpful comments and suggestions.

\section{References}

Aghion P, Dewatripont M, Hoxby C, Mas-Colell A and Sapir A (2008) Higher Aspirations: An Agenda for Reforming European Universities. Brussels: Bruegel.

Aghion P, Dewatripont M, Hoxby C, Mas-Colell A and Sapir A (2010) The Governance and Performance of Universities: Evidence from Europe and the US. Economic Policy 25(61): 7-59.

Ansell BW (2008) University Challenges: Explaining Institutional Change in Higher Education. World Politics 60(1): 189-230. 
Bouwma I, Liefferink D, Apeldoorn RV and Arts B (2016) Following Old Paths or Shaping New Ones in Natura 2000 Implementation? Mapping Path Dependency in Instrument Choice. Journal of Environmental Policy \& Planning 18(2): 214-233.

Braumoeller BF (2015) Guarding Against False Positives in Qualitative Comparative Analysis. Political Analysis 23(4): 471-487.

Braun D and Merrien F-X (eds.) (1999) Towards a New Model of Governance for Universities?. London: Jessica Kingsley Publishers.

Braga M, Checchi D and Meschi E (2013) Educational Policies in a Long-Run Perspective. Economic Policy 28(73): 45-100.

Bressers H, Laurence TA and O’Toole J (2005) Instrument Selection and Implementation in a Networked Context. In Eliades P, Hill M and Howlett M (eds.), Designing Government: From Instruments to Governance. Montreal, QC and Kingston, ON: McGill-Queen's University Press, 132-153.

Capano G (2011) Government Continues to Do Its Job. A Comparative Study of Governance Shifts in the Higher Education Sector. Public Administration 89(4): 1622-1642.

Capano G, Howlett M and Ramesh M (eds.) (2015) Varieties of Governance. London: Palgrave.

Capano G, Rayner J and Zito AR (2012) Governance from the Bottom Up: Complexity and Divergence in Comparative Perspective. Public Administration 90(1): 56-73.

Capano G and Regini M (2014) Governance Reforms and Organizational Dilemmas in European Universities. Comparative Education Review 56(1): 73-103.

Capano G, Regini M and Turri M (2016) Changing Governance in Universities. Italian Higher Education in Comparative Perspective. London: Palgrave MacMillan.

Capano G and Pritoni A (2019) Varieties of Hybrid Systemic Governance in European Higher Education. Higher Education Quarterly 73(1): 10-28.

Capano G and Turri M (2017) Same Governance Template but Different Agencies. Types of Evaluation Agencies in Higher Education. Comparing England, France, and Italy. Higher Education Policy 30(2): 225-243.

CHEPS (2006) The Extent and Impact of Higher Education Governance Reform Across Europe. Final Report to the Directorate General for Education and Culture OfEuropean Commission, http://ec.europa. eu/education/ (accessed 12 January 2018).

Clark BR (1983) The Higher Education System. Academic Organization in Cross National Perspective. Berkeley, CA: University of California Press.

Considine M and Lewis JM (1999) Governance at Ground Level: The Frontline Bureaucrat in the Age of Markets and Networks. Public Administration Review 59(6): 467-480.

Dobbins M and Knill C (2009) Higher education policies in central and eastern Europe: Convergence toward a common model? Governance 22(3): 397-430.

Dobbins M and Knill C (2014) Higher Education Governance and Policy Change in Western Europe. Basingstoke: Palgrave Macmillan.

Enders J, De Boer H and Weyer E (2013) Regulatory Autonomy and Performance: The Reform of Higher Education Revisited. Higher Education 65(1): 5-23.

Flannery D and O'Donoghue C (2011) The Life-Cycle Impact of Alternative Higher Education Finance Systems in Ireland. The Economic and Social Review 42(3): 237-270.

Gornitzka Å, Kogan M and Amaral A (eds.) (2005) Reform and Change in Higher Education. Dordrecht: Springer.

Hacker JS (2004) Reform Without Change, Change Without Reform: The Politics of US Health Policy Reform in Comparative Perspective. In Levin MA and Shapiro M (eds.), Transatlantic Policymaking in an Age of Austerity: Diversity and Drift. Washington, DC: Georgetown University Press, 13-63.

Hood C (1983) The Tools of Government. London: Macmillan.

Horeau C, Ritzen J and Marconi G (2013) Higher Education and Economic Innovation, a Comparison of European Countries. IZA Journal of European Labor Studies 2(1): 2-24.

Howlett M (2000) Managing the 'Hollow State': Procedural Policy Instruments and Modern Governance. Canadian Public Administration 43(4): 412-431.

Howlett M (2005) What is a Policy Instrument? Policy Tools, Policy Mixes and Policy-Implementation Styles. In Eliadis P, Hill MM and Howlett M (eds.), Designing Government. From Instruments to Governance. Montreal, QC and Kingston, ON: McGill-Queen's University Press, 311-350. 
Howlett M (2009) Governance Modes, Policy Regimes and Operational Plans: A Multi-Level Nested Model of Policy Instrument Choice and Policy Design. Policy Sciences 42(1): 73-89.

Howlett M (2011) Designing Public Policies: Principles and Instruments. London: Routledge.

Howlett M and Del Rio P (2015) The Parameters of Policy Portfolios: Verticality and Horizontality in Design Spaces and Their Consequences for Policy Mix Formulation. Environment and Planning C: Politics and Space 33, 1233-1245.

Huisman J (eds.) (2009) International Perspectives on the Governance of Higher Education. London: Routledge. Huitema D and Meijerink S (eds.) (2009) Water Policy Entrepreneurs: A Research Companion to Water Transitions Around the Globe. Camberley, UK and Northampton, MA, USA: Edward Elgar Publishing.

Knott JH and Payne A (2004) The Impact of State Governance Structures on Management and Performance of Public Organizations: A Study of Higher Education Institutions. Journal of Policy Analysis and Management 23(1): 13-30.

Koontz TM and Thomas CW (2012) Measuring the Performance of Public-Private Partnerships: A Systematic Method for Distinguishing Outputs from Outcomes. Public Performance \& Management Review 35(4): 769-786.

Ingram H and Schneider AI (1990) The Behavioral Assumptions of Policy Tools. The Journal of Politics 52(2): 510-529.

Jordan A, Benson D, Zito A and Wurzel RKW (2012) Environmental Policy: Governing by Multiple Policy Instruments?. In Richardson J (ed.), Constructing a Policy State? Policy Dynamics in the EU. Oxford: Oxford University Press, 104-124.

Lazzaretti L and Tavoletti E (2006) Governance Shifts in Higher Education: A Cross National Comparison. European Educational Research Journal 5(1): 18-37.

Liefner I (2003) Funding, Resource Allocation, and Performance in Higher Education Systems. Higher Education 46(4): 469-489.

Linder S and Peters GB (1990) An Institutional Approach to the Theory of Policymaking: The Role of Conscious Choice in Policy Formulation. The Journal of Theoretical Politics 2, 59-83.

Maassen P and Olsen JP (eds.) (2007) University Dynamics and European Integration. Dordrecht: Springer.

Neave G (2012) The Evaluative State, Institutional Autonomy and Re-engineering Higher Education in Western Europe. London: Palgrave.

Organization for Economic Cooperation and Development (OECD) (1998) Education at a Glance 2008. Paris: OECD.

Organization for Economic Cooperation and Development (OECD) (2007) Instruments Mixes for Environmental Policy. Paris: OECD.

Organization for Economic Cooperation and Development (OECD) (2010) OECD Science,Technology and Industry Outlook 2010. Paris: OECD.

Organization for Economic Cooperation and Development (OECD) (2016) Education at a Glance 2016. Paris: OECD.

Paradeise C, Reale E, Bleiklie I and Ferlie E (eds.) (2009) University Governance. Western European Comparative Perspectives. Dordrecht: Springer.

Phidd RW and Doern GB (eds.) (1983) Canadian Public Policy: Ideas, Structure, Process. Toronto, ON: Methuen.

Pierson C (2004) The Modern State. London: Routledge.

Rabovsky TM (2012) Accountability in Higher Education: Exploring Impacts on State Budgets and Institutional Spending Patterns. Journal of Public Administration Research and Theory 22(4): 675-700.

Ragin CC (1987) The Comparative Method. Berkeley, CA: University of California Press.

Ragin CC (2000) Fuzzy-Set Social Science. Chicago, IL: The University of Chicago Press.

Ragin CC (2006) Set Relations in Social Research: Evaluating their Consistency and Coverage. Political Analysis 14(3): 291-310.

Ragin CC (2008) Redesigning Social Inquiry: Fuzzy Sets and Beyond. Chicago, IL: The University of Chicago Press.

Richardson R and Martinez M (2009) Policy and Performance in American Higher Education: An Examination of Cases Across State Systems. Baltimore, MD: The John Hopkins University Press.

Rihoux B, Álamos-Concha P, Bol D, Marx A and Rezsöhazy I (2013) From Niche to Mainstream Method? A Comprehensive Mapping of QCA Application in Journal Articles from 1984 to 2011. Political Research Quarterly 66(1): 175-184. 
Rihoux B and Ragin CC (eds.) (2009) Configurational Comparative Methods: Qualitative Comparative Analysis (QCA) and Related Techniques. Los Angeles, CA, USA: Sage.

Ring I and Schroter-Schlaack C (2010) Instrument Mixes for Biodiversity Policies. Leipzig: Helmholtz Centre for Environmental Research.

Rohlfing I (2018) Power and False Negatives in Qualitative Comparative Analysis: Foundations, Simulation and Estimation for Empirical Studies. Political Analysis 26(1): 72-89.

Rosa MJ and Amaral A (eds.) (2014) Quality Assurance in Higher Education. Basingstoke, UK: PalgraveMacmillan.

Rutherford A and Rabovsky T (2014) Evaluating Impacts of Performance Funding Policies on Student Outcomes in Higher Education. The Annals of The American Academy of Political and Social Science 655(1): 185-209.

Salamon LM (ed.) (2002) The Tools of Government: A Guide to the New Governance. Oxford: Oxford University Press.

Schaffrin A, Sewerin S and Seubert S (2014) The Innovativeness of National Policy Portfolios - Climate Policy Change in Austria, Germany, and the UK. Environmental Politics 23(5): 860-883.

Schneider CQ and Rohlfing I (2013) Combining QCA and Process Tracing in Set-Theoretic MultiMethod Research. Sociological Methods \& Research 42(4): 559-597.

Schneider CQ and Wagemann C (2010) Standards of Good Practice in Qualitative Comparative Analysis (QCA) and Fuzzy-Sets. Comparative Sociology 9(3): 397-418.

Schneider CQ and Wagemann C (2012) Set-Theoretic Methods for the Social Sciences. Cambridge: Cambridge University Press.

Shattock ML (ed.) (2014) International Trends in University Governance. London: Routledge.

Tandberg D and Hillman N (2014) State Higher Education Performance Funding: Data, Outcomes, and Policy Implications. Journal of Education Finance 39(3): 222-243.

Tollefson C, Zito AR and Gale F (2012) Symposium Overview: Conceptualizing New Governance Arrangements. Public Administration 90(1): 3-18.

Tosun J (2013) Risk Regulation in Europe. Assessing the Application of the Precautionary Principle. New York: Springer.

Trakman L (2008) Modelling University Governance. Higher Education Quarterly 62(1-2): 63-83.

Treib O, Bahr H and Falkner G (2007) Modes of Governance: Towards a Conceptual Clarification. Journal of European Public Policy 14(1): 1-20.

Vedung E (1998) Policy Instruments: Typologies and Theories. In Bemelmans-Videc M-L, Rist RC and Vedung E (eds.), Carrots, Sticks, and Sermons: Policy Instruments and Their Evaluation. New Brunswick, NJ: Transaction, 21-58.

Vis B (2012) The Comparative Advantages of fsQCA and Regression Analysis for Moderately Large-N Analysis. Sociological Methods \& Research 41(1): 168-198.

Volkwein JF and Tandberg D (2008) Measuring Up: Examining the Connections Among State Structural Characteristics, Regulatory Practices, and Performance. Research in Higher Education 49(2): 180-197.

Willemse N and De Beer P (2012) Three Worlds of Educational Welfare States? A Comparative Study of Higher Education Systems Across Welfare States. Journal of European Social Policy 22(2): 105-117.

Williams R, de Rassenfosse G, Jensen P and Marginson S (2013) The Determinants of Quality National Higher Education Systems. Journal of Higher Education Policy and Management 35(6): 599-611.

Winter-Ebmer R and Wirz A (2002) Public Funding and Enrolment into Higher Education in Europe. IZA Discussion Papers 503. Berlin: Institute for the Study of Labor (IZA).

Woodside K (1983) The Political Economy of Policy Instruments: Tax Expenditures and Subsidies. In Atkinson MM and Chandler MA (eds.), The Politics of Canadian Public Policy. Toronto, ON: University of Toronto Press, 173-197.

Cite this article: Capano G, Pritoni A, Vicentini G. 2020. Do policy instruments matter? Governments' choice of policy mix and higher education performance in Western Europe. Journal of Public Policy 40: 375-401, doi: 10.1017/S0143814X19000047 